\title{
RETURN TO PLAY AFTER ANTERIOR CRUCIATE LIGAMENT RECONSTRUCTION
}

\author{
RETORNO AO ESPORTEAPÓS A RECONSTRUÇÃO DO LIGAMENTO CRUZADO ANTERIOR
}

RETORNO AL DEPORTEDESPUÉS DE RECONSTRUCCIÓN DEL LIGAMENTO CRUZADO ANTERIOR

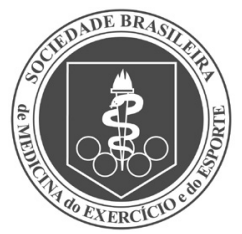

SPECIAL ARTICLE

ARtIGO ESPECIAL ARTICULO ESPECIAL
Rodrigo A. Goes ${ }^{1}$ (ID

(Orthopedic Physician)

Victor R. A. Cossich2,3 (D) (Physical Education Professional)

Bráulio R. França ${ }^{1,4}$ (DD

(Physiotherapist)

André Siqueira Campos 5 (ID

(Orthopedic Physician)

Gabriel Garcez A. Souza' (ID (Orthopedic Physician)

Ricardo do Carmo Bastos' ${ }^{1}$ (ID (Orthopedic Physician) João A. Grangeiro Neto' (ID) (Orthopedic Physician)

1. Instituto Nacional de Traumatologia e Ortopedia Jammil Haddad (INTO), Center for Specialized Care in Sports Trauma, Rio de Janeiro, RJ, Brazil. 2. Instituto Nacional de Traumatologia e Ortopedia Jammil Haddad (INTO), Research Division, Neuromuscular Research Laboratory, Rio de Janeiro,

RJ, Brazil.

3. Universidade Federal do Rio de Janeiro, School of Physical Education and Sport (UFRJ-EEFD), Rio de Janeiro, RJ, Brazil. 4. Instituto Nacional de Traumatologia e Ortopedia Jammil Haddad (INTO), Physiotherapy Department, Rio de Janeiro,

RJ, Brazil.

5. Hospital Federal dos Servidores do Estado do Rio de Janeiro, Knee Group, Rio de Janeiro, RJ, Brazil.

\section{Correspondence:}

Rodrigo Araujo Goes

Divisão de Traumatologia e

Ortopedia (DITRO).

Avenida Brasil, 500, $2^{\circ}$ andar,

Caju, Rio de Janeiro, RJ, Brazil. 20940-070.

rodrigogoes4@yahoo.com.br

\section{ABSTRACT}

The anterior cruciate ligament (ACL) tear represents more than half of all knee injuries in sports that involve body rotations and sudden changes of direction. Discharging the athlete for return to play (RTP) post-ACL reconstruction (ACLR) is a difficult task with multidisciplinary responsibility. For many years, a six-month period post-ACLR was adopted as the only criterion for RTP. However, it is now suggested that RTP should not be exclusively time-based, but to clinical data and systematic assessments. Despite the importance of post-ACLR factors for RTP, pre- and peri-ACLR factors must also be considered. Historically, ACLR is performed with the hamstring or autologous patellar tendons, although the choice of graft is still an open and constantly evolving theme. Anterolateral ligament reconstruction and repair of meniscal ramp tear associated with ACLR have recently been suggested as strategies for improving knee joint stability. Subjective questionnaires are easy to apply, and help identify physical or psychological factors that can hamper RTP. Functional tests, such as hop tests and strength assessment by means of isokinetic dynamometers, are fundamental tools for decision making when associated with clinical evaluation and magnetic resonance imaging. Recently, the capacity to generate force explosively has been incorporated into the muscle strength assessment. This is quantified through the rate of torque development (RTD). Due to characteristics inherent to the practice of sport, there is an extremely short time available for produce strength. Thus, RTD seems to better represent athletic demands than the maximum strength assessment alone. This review investigates the pre-, peri- and post-ACLR factors established in the literature, and shares our clinical practice, which we consider to be best practice for RTP. Level of evidence $V$; Specialist opinion.

Keywords: Anterior cruciate ligament; Return to sports; Meniscus; Muscle strength; Rehabilitation; Knee joint.

\section{RESUMO}

A ruptura do ligamento cruzado anterior (LCA) representa mais da metade das lesões do joelho em esportes que envolvem rotações e mudanças repentinas de direção. A liberação do atleta para o retorno ao esporte (RAE) depois da reconstrução do LCA (RLCA) é uma tarefa difícil, de responsabilidade multidisciplinar. Por muitos anos, o período de seis meses pós-RLCA foi utilizado como único critério para RAE. Contudo, atualmente, sugere-se que o RAE não deve estar atrelado exclusivamente ao tempo, mas a dados clínicos e avaliações sistemáticas. Apesar da importância dos fatores pós-RLCA para o RAE, os fatores pré- e peri-RLCA também devem ser contemplados. Historicamente, a RLCA é realizada com tendões isquiotibiais ou patelares autólogos, apesar da escolha do enxerto ainda ser um tema em aberto e em constante evolução. Recentemente, a reconstrução do ligamento anterolateral e o reparo da lesão na rampa meniscal associadas à RLCA têm sido sugeridas como estratégias para melhorar a estabilidade articular do joelho. Questionários subjetivos são de fácil aplicação e ajudam a identificar fatores físicos ou psicológicos que possam dificultar o RAE. Testes funcionais como os hop tests e a avaliação de força com dinamômetros isocinéticos são ferramentas fundamentais na decisão quando aliadas à avaliação clínica e de ressonância magnética. Recentemente, tem-se incorporado ao escopo de avaliação da força muscular a capacidade de gerar força de maneira explosiva, mensurada através da taxa de desenvolvimento de torque (TDT). Devido a características inerentes a prática esportiva os tempos disponíveis para produção de força são demasiadamente pequenos e, sendo assim, a TDT parece representar melhor as demandas esportivas do que a avaliação isolada de força máxima. Nesta revisão, foram reunidos fatores pré, peri e pós-RLCA estabelecidos na literatura, assim como foi compartilhada nossa prática clínica, que consideramos ser a melhor para o RAE. Nível de evidência V; Opinião do especialista.

Descritores: Ligamento cruzado anterior; Retorno ao esporte; Menisco; Força muscular; Reabilitação; Articulação dojoelho.

\section{RESUMEN}

La ruptura del ligamento cruzado anterior (LCA) representa más de la mitad de las lesiones de rodilla en deportes que involucran rotaciones y cambios repentinos de dirección. La liberación del atleta para el retorno al deporte (RAD) después de la reconstrucción del LCA (RLCA) es una tarea dificil, de responsabilidad multidisciplinaria. Durante muchos años, el período de seis meses post-RLCA fue usado como único criterio para RAD. Sin embargo, actualmente, se sugiere que el RAD no debe estar vinculado exclusivamente al tiempo, sino a datos clínicos y evaluaciones sistemáticas. A pesar de la importancia de los factores post-RLCA para el RAD, también deben ser contemplados los factores pre y peri-RLCA. Históricamente, la RLCA es realizada con tendones isquiotibiales o patelares autólogos, a pesar de que la 
elección del injerto aún sea un tema abierto y en constante evolución. Recientemente, la reconstrucción del ligamento anterolateral y la reparación de la lesión en la rampa meniscal asociadas a la RLCA han sido sugeridas como estrategias para mejorar la estabilidad articular de la rodilla. Los cuestionarios subjetivos son de fácil aplicación y ayudan a identificar los factores físicos o psicológicos que pueden dificultar el RAD. Los tests funcionales como los hop tests y la evaluación de fuerza con dinamómetros isocinéticos son herramientas fundamentales en la decisión cuando se combinan a la evaluación clínica y de resonancia magnética. Recientemente, se ha incorporado al alcance de evaluación de la fuerza muscular, la capacidad de generar fuerza de manera explosiva, medida a través de la tasa de desarrollo de torque (TDT). Debido a características inherentes a la práctica deportiva, los tiempos disponibles para producción de fuerza son demasiado pequeños y, siendo así, la TDT parece representar mejor las demandas deportivas que la evaluación aislada de fuerza máxima. En esta revisión fueron reunidos factores pre, periy post-RLCA establecidos en la literatura, asícomo fue compartida nuestra práctica clínica, que consideramos la mejor para el RAD. Nivel de evidencia V; Opinión del especialista.

Descriptores: Ligamento cruzado anterior; Volver al deporte; Menisco; Fuerza muscular; Rehabilitación; Articulación de la rodilla.

\section{INTRODUCTION}

The rupture of the anterior cruciate ligament $(\mathrm{ACL})$ represents up to $64 \%$ of all knee injuries in sports that involve rotations and changes in direction. ${ }^{1}$ With the evolution of surgical techniques and rehabilitation/ training protocols, there is currently an increase in the number of athletes who return to pre-injury sports after surgery for $A C L$ reconstruction (ACLR). ${ }^{2,3}$

The return to play (RTP) can be defined as the time necessary for the post-ACLR athlete to be able to compete at the same previous level. ${ }^{4}$ For many years, the determining criterion for the RTP post-ACLR was the six-month period elapsed. ${ }^{3}$ However, recent findings discourage using the temporal criterion in isolation..$^{5-8}$ The current trend is to characterize the RTP as a continuous process with three subphases: return to participation, return to playing and return to performance. These subphases should be guided not only by time frames, but by objective clinical criteria and physical testing. ${ }^{6}$

Post-ACLR patients commonly demonstrate neuromuscular deficits in the lower limbs, ${ }^{6,7,9}$ which can last up to two years. ${ }^{10}$ Such deficits are considered a risk factor for re-rupture, $A C L$ rupture in the contralateral limb and early development of osteoarthritis. ${ }^{5,8}$ Thus, monitoring post-ACLR patients through physical tests with objective control parameters is mandatory to release the patient/athlete to the RTP without restrictions. ${ }^{11}$ Although proposals have been made, ${ }^{8,12}$ there is still no standardized battery of tests. ${ }^{13,14}$ However, it is not uncommon for studies to report the use of assessments of the muscular strength of knee extensors (EXT) and flexors (FLEX) 6,15 and/or the different variations of hop tests. ${ }^{6,16}$ In addition to these, it is common to use self-assessment questionnaires that are easy to apply and low cost.

Shelbourne et al. ${ }^{17}$ followed more than 1400 athletes, for a minimum period of 5 years, submitted to ACLR to assess the rate of recurrence of ipsilateral and contralateral injuries. They observed that women have more than twice the chance of having a contralateral injury, as well as about $17 \%$ of athletes under 18 years old suffered graft rupture and that number progressively decreased with advancing age. In professional athletes, the main concern is neglected associated injuries and accelerated rehabilitation protocols. The anxiety of the athlete and the coaching staff can anticipate their return to competitions and be decisive for the graft failure. The graft rupture is potentially catastrophic and the RTP rate is much lower when dealing with a surgical revision. Among the causes of failure, four must be considered before scheduling a review: increased tilt of the plateau (tibial slope), varus alignment, anterolateral ligament injury (ALL) and meniscal injury. Currently, the correction of these factors is encouraged when identified. ${ }^{18}$
In order to be successful post-ACLR, multidisciplinary rehabilitation/ training is indispensable together with the determination of objective criteria. Although the literature has advanced, there are still no established and widely accepted parameters for the athlete's release to the RTP, making this a challenging decision. Therefore, the objective of this review was to descrive and discuss factors in the pre-, per- and post-operative period established in the literature, as well as to share our clinical practice, which we consider to be the best practices for a safer RTP.

\section{Pre- and per-operative factors \\ Graft type}

The graft determination for primary ACLR is still a controversial topic. ${ }^{19}$ Many factors are studied in order to determine the best graft, as well as its ideal characteristics, such as diameter, failure rate and RTP. ${ }^{20}$ Bjornsson et al. ${ }^{20}$ compared the use of hamstring tendons to the patellar tendon and did not find different rates of failure or complications. Recently, the use of quadriceps tendon has received attention for showing equivalent functional results, patient satisfaction and low rates of failure and complications at the donor site. ${ }^{19}$ The diameter of the graft seems to have an influence on the ACLR's risk of failure. Grafts of eight millimeters in diameter or more have lower failure rates than thinner grafts. ${ }^{21}$ Legnani et al. ${ }^{22}$ found no significant difference in the RTP rate for patients who used autologous contralateral hamstrings compared to the use of allografts. However, patients who used an autologous graft demonstrated an RTP in 7.7 months, while those who used a tissue bank graft took an average of 9.8 months. Despite all efforts in the search for the best graft, the autologous hamstring and patellar tendons continue to be the main choices.

\section{Reconstruction of the anterolateral ligament and repair of the meniscal ramp lesion associated with the anterior cruciate liga- ment reconstruction}

The importance of ALL in post-ACLR knee stability is a widely discussed topic. ${ }^{23-25}$ DePhillipo et al. ${ }^{26}$ observed only $1.1 \%$ graft rupture when ACLR was associated with ALL reconstruction (ALLR), against $16.3 \%$ of failures in isolated ACLR. Delaloye et al. ${ }^{26}$ reported excellent clinical results with a two-year follow-up post-ACLR combined with ALLR, with a graft rupture rate of $10.8 \%$ (quadruple hamstring graft), $6.8 \%$ (patellar graft) and only $4.1 \%$ with the associated ALLR, regardless of the graft used in the ACLR. In addition, they observed a reduction in the reoperation rate to $8.7 \%$ when associated with ALLR compared to isolated ACLR.

Redler et al. ${ }^{24}$ evaluated patients who underwent ACLR revision with $A L L$ reinforcement performed with an iliotibial band with an average follow-up of 10 years. Their results showed that only $7.6 \%$ cases evolved 
with loosening (Lachman > 5mm contralateral) and there was no graft rupture in any case, suggesting that $A L L$ reinforcement decreases the risk of failure in an ACLR review. Yoo et al. ${ }^{25}$ found no clinical differences in knee stability after isolated ACLR in patients who had concomitant injury of ALL. However, when submitting the patient to post-ACLR arthroscopy, they found a lower graft tension in those patients who had concomitant ALL injury (87.5\%) versus $20.5 \%$ in the group with intact ALL, suggesting that the neglected ALL injury can cause graft loosening and rupture.

Recent work suggests that many failures in ACLR may be due to the neglect of the meniscus-capsular lesion in the posterior horn of the medial meniscus, or zone IV, also called lesions in the meniscal ramp. ${ }^{27,28}$ Di Vico et al. ${ }^{28}$ evaluated patients with ACL rupture, making posteromedial portal in all those who had some degree of instability in the posterior horn of the medial meniscus. They found a 9.6\% prevalence of injuries on the ramp among all patients with $\mathrm{ACL}$ injuries. It was also observed that the existence of this meniscal injury was greater in patients treated six months after the injury, suggesting that ACL insufficiency is a predisposing factor. Results that corroborate the observations of Liu et al., ${ }^{29}$ who reported $16.6 \%$ of this association in patients with ACL rupture, especially men below 30 and lesions lasting more than six months ( 6 months $=12.7 \%$ and $>6$ months $=22.8 \%$ ).

The ramp injury can reach $23 \%$ of cases in the $A C L$ presence and rupture, ${ }^{30}$ reinforcing the importance of its diagnosis. They signaled the need to conduct research through the posteromedial portal, at risk of diagnostic loss in up to $15 \%$ of cases. In addition, patients who underwent repair of the lesion on the ramp and had $A L L$ reconstruction associated with $A C L$ were twice as less likely to need revision of the meniscal suture than patients with isolated ACLR. ${ }^{31}$ When there is an associated lesion of the menisci, there is a greater tibial acceleration in the rotation movements, thus, the integrity and repair of the menisci and the extracapsular anterolateral reinforcement (for rotational instability), should be performed whenever possible. ${ }^{32}$

Recently, Heilpern et al. ${ }^{33}$ simulated cadaveric ramp injuries and repaired with an all-inside suture technique. In their results, only $2.5 \%$ of the devices used failed, and all that had good fixation were efficient in maintaining the stability of the posterior horn of the medial meniscus. The efficacy of integrated approaches to treating injuries to the medial meniscus ramp and ALL injuries still lack further evidence. However, most results encourage the surgeon to perform ALL reconstruction whenever there is injury or rotational instability, and perform meniscal repair whenever possible to decrease the rate of graft failure and overload. In competitive athletes, indicating reconstruction of the $A L L$ and suturing the menisci can represent a safer RTP and save them from a new surgery, which often shortens their career.

\section{Postoperative factors}

\section{Rehabilitation protocols}

It has been suggested that the RTP depends more on a rigorous rehabilitation program than on the surgical technique or the choice of graft used.' 'Like the final RTP criteria, most post-ACLR rehabilitation protocols are solely time-based. In fact, it is important to respect the healing and "ligamentization" period of the grafts so that they are not subjected to stresses that can lead to loosening, incompetence and/ or risk of new ruptures, especially at times when the sensorimotor and neuromuscular functions are still not able to react properly. But recently, it has been suggested to design the rehabilitation protocols in phases, and to use objective criteria for progression between them. ${ }^{34-36}$ This strategy improve communication between the members of the rehabilitation team (physicians, physiotherapists, physical educators, nutritionists, psychologists, etc.) providing a better understanding on wich phase of the rehabilitation process the athlete is. Treatment and training become more effective since they are carried out at the necessary intensity, respecting the principle of overload, but with a low risk of injury.

\section{Image criteria}

Li et al. ${ }^{37}$ initially did not find clinical importance in graft signal changes in magnetic resonance imaging (MRI) performed post-ACLR and did not associate the findings with graft strength/resistance, but suggest that the decrease in graft signal intensity is directly related to better scores on the International Knee Documentation Committee (IKDC), especially after 12 months of surgery. Hofbauer et al. ${ }^{38}$ compared MRI of post-ACLR knees with those of healthy knees. After six months of ACLR, they observed a difference in the intensity of the graft signal in relation to the original $A C L$ in its substance and in the femoral insertion, and without difference in the tibial insertion. They suggested that this period is precocious for RTP, even if the functional and muscle strength criteria are met, as there is no biological maturity of the graft ("ligamentization").

The combination of graft signal intensity and volume should be considered for the assessment of graft incorporation in ACLR surgery. Wider grafts with low signal intensity were associated with better performances after five years. These patients had better results in the evaluation of functional tests, pain, quality of life questionnaires and symptoms. ${ }^{3}$ In a recent review, the MRI graft signal with six months of ACLR was evaluated and repeated with 12 months in parallel to the IKDC questionnaire. They observed that in the evolution from six to 12 months there was a decrease in the signal on MRI, and an improvement in the IKDC score. The results suggest that the greater the graft maturity, the better the surgery functional results. ${ }^{37}$ These results corroborate those found by Biercevicz et al., ${ }^{39}$ who correlated the graft maturity, measured by intensity and diameter at MRI, and the clinical and functional results (residual laxity and single hop-test).

\section{Subjective questionnaires}

The use of questionnaires is a valuable and complementary tool in decision-making about the RTP. They are easy to apply instruments and help to identify factors, whether physical or psychological, that may hinder or prevent RTP. Barber-Westin and Noyes ${ }^{9}$ observed that only one of 264 studies used validated questionnaires as a criterion for the RTP. More recently, Grassi et al. ${ }^{40}$ observed that $90 \%$ of the studies used one or more clinical scores for evaluation, demonstrating that an increasing importance has been attributed to these forms of evaluation. Specific tools that report on the patient's personal experience such as the IKDC, the Tampa Scale for Kinesiophobia (TSK) and the Anterior Cruciate Ligament-Return to Sport after Injury Scale (ACL-RSI) have been documented as important measures in the post-ACLR assessment. 9,41-45

The IKDC allows global assessment for ACL injuries, and has been used as a criterion for post-ACLR RTP. ${ }^{46}$ Low IKDC scores seem to be associated with a greater likelihood of unsatisfactory results in muscle strength tests, hop tests and the degree of patient satisfaction. 43,46 The Tampa Scale for Kinesiophobia (TSK) assesses fear related to pain caused by movement. ${ }^{43}$ Zwolski et al. ${ }^{46}$ found that in the TSK short version, TSK-11, patients who did not return to sport had slightly higher scores.

The ACL-RSI assesses the psychological impact on the post-ACLR RTP. Patients who returned to sport had higher scores (76.8 \pm 15.0 points) when compared to patients who did not return $(48.7 \pm 27.2 \text { points) })^{43,47}$ suggesting that psychological factors may influence the outcome and that strategies to increase athletes' confidence are beneficial. ${ }^{43,47}$ The ACL$\mathrm{RSI}$ is composed of 12 items subdivided into three themes: emotional, performance and risk assessment. ${ }^{48}$

Likewise, Nawasreh et al. ${ }^{14}$ found a higher rate of RTP in athletes who performed well in a battery of tests (quadriceps isometric strength index, hop tests and specific questionnaires - Knee Outcome Survey - activities of Daily Living Subscale (KOS-ADLS) and Global Rating Scale of Perceived Function (GRS). 


\section{Functional tests}

Noyes et al. ${ }^{16}$ proposed a set of four jump tests (single leg, triple and crossover hop for distance; and $6 \mathrm{~m}$ timed hop) with the proposal to provide an objective and functional measure related to sports demands that involve jumping, pivoting and constant changes of direction. Hop tests can be performed easily, requiring little specialized equipment and training for their application. In addition, it has already proved to be a reliable measure to monitor patients in post-ACLR ${ }^{49}$ Studies report a gradual improvement in jumping performance, reaching a limb symmetry index $(L S I) \geq 90 \%$ in the period between 6 to 9 months after $A C L R .9,11$

Recently, Herrington et al. ${ }^{50}$ evaluated the correlation between EXT knee strength and performance in functional tests post-ACLR in 15 professional soccer players. At the time of RTP, they observed that $80 \%$ of the athletes failed the LSI criterion ( $\geq 90 \%$ ) in the strength test, although $75 \%$ of them passed the same criterion for the hop test. Barfod et al. ${ }^{51}$ concluded that the single leg hop test cannot be used to replace the knee EXT strength measure, since satisfactory values in the jump test can be achieved without the strength levels being achieved as well. In addition, there is evidence that the LSI measured for distance should not be used as an isolated RTP method. ${ }^{52}$

The Knee Santy Athletic Return to Sport Test (K-STARTS) is a score that provides data on post-ACLR conditions..$^{53} \mathrm{~K}$-STARTS is based on eight components evaluated in seven tests. Each component receives a score from 0 to 3, with a maximum score of 21 points. The following tests are used: ACL-RSI, single-leg landing, single hop, triple hop, side hop, crossover hop and Modified Illinois change of direction test. In addition to these tests, there may be a discount of three penalty points if the patient presents dynamic valgus on the single leg landing. The result generates a global and individualized analysis of each test, helping the multiprofessional team to focus on what is not yet suitable for the RTP (Table 1).

\section{Muscular strength}

Different methods have been used to assess muscle strength preand post-ACLR. ${ }^{8,14}$ Most studies used isokinetic dynamometers, but the protocols have a lot of variation as to the type of muscle action, angular speed, number of repetitions and range of motion. ${ }^{8,51}$ However, it must be said that the vast majority of studies used concentric actions with a speed of $60 \%$ s for EXT and FLEX of the knee. ${ }^{15}$ The weakness of the EXT and FLEX of the knee are commonly reported post-ACLR at different time frames. 15,54 However, data suggest that recovery/strength gain depends on adherence to the rehabilitation/training program. ${ }^{54}$

In the absence of normative data for comparison, analyses are performed through LSI. The LSI is used to establish a proportionality value between the limb involved with the non-operated contralateral, $90 \%$ is considered as an absence of deficit. ${ }^{6,7}$ A recent study suggests that obtaining an appropriate LSI together with the nine-month post-ACLR time criterion reduces the chance of graft rupture by $84 \%{ }^{5}$ However, it is noteworthy that the use of LSI can mask the existence of bilateral deficits. ${ }^{55,56}$

In addition to the LSI among homologous muscle groups, maintaining the FLEX/EXT ratio of the knee is an indirect indicator of the joint functional stability. Thus, deficit in the FLEX/EXT ratio has been considered a risk factor for $\mathrm{ACL}$ injuries. ${ }^{57}$ This assumption emerges from the fact that the knee FLEXs act as ACL synergists, acting in the prevention of the anterior translation of the tibia in relation to the femur. ${ }^{8}$ In fact, Kyritsis et al. ${ }^{8}$ evaluated a total of 158 athletes and observed that the subjects who presented lower values for the FLEX/EXT ratio at a speed of $60 \%$ had a greater chance of graft rupture (Figure 1).

In addition to the EXT and FLEX groups of the knee, the abductor and hip external rotator muscles are also important in reducing the risk of ACL rupture, and should also be monitored ${ }^{58}$ The weakness in these muscles can cause the femur internal rotation, together with the knee dynamic valgus, movement patterns that were previously associated with $\mathrm{ACL}$ rupture. ${ }^{59}$ However, few references are found that assessed hip strength in post-ACLR. ${ }^{11,60}$

Conflicting results are reported regarding the effect of the type of graft used for ACLR on the EXT and FLEX knee strength. ${ }^{11,61}$ A meta-analysis demonstrated that after 12 months of ACLR, patients who received a graft from the patellar tendon presented reduced strength values for EXT, while patients who received the flexor tendon demonstrated a strength deficit for FLEX, suggesting that such findings are related to the graft donor area, a recently reinforced view. ${ }^{15,62}$

Recently, it has been suggested that the ability to produce explosive strength in short periods of time $(<300 \mathrm{~ms})$ is more representative of sporting capacity than maximum strength (eg, peak isokinetic or isometric torque). ${ }^{63}$ During sports activities, the time available to produce muscle strength/torque is infinitely less than the time needed to reach maximum muscle capacity. Previous studies have observed that the time between contact with the ground and $\mathrm{ACL}$ rupture lasted on average $50-60 \mathrm{~ms},{ }^{59}$ suggesting that this is the window of time available for any attempt at dynamic joint stabilization provided by muscle contraction. The rate of torque development (RTD) assesses this condition by measuring how much strength/torque an individual is capable of producing in fractions of time between $50-250 \mathrm{~ms}$ from the contraction onset..$^{63}$ Therefore, it has been proposed to include it in batteries for the evaluation and control of the athlete for ${ }^{64}$ RTP. (Figure 2)

Table 1. Tests and scoring equivalence for K-START.

\begin{tabular}{|c|c|c|c|c|}
\hline Test & $\begin{array}{l}\text { ACL - RSI } \\
\text { (Previous Cruciate Ligament - } \\
\text { Return to Sport after Injury) }\end{array}$ & $\begin{array}{l}\text { QASLS } \\
\text { (Quality Assessment of } \\
\text { Single-Leg Loading) }\end{array}$ & Hop tests & $\begin{array}{c}\text { MICODT } \\
\text { (Modified Illinois Change } \\
\text { of Direction Test) }\end{array}$ \\
\hline Description & Psychological readiness questionnaire & $\begin{array}{l}\text { Qualitative analysis of the motor } \\
\text { strategy of body segments } \\
\text { during single-leg loading. }\end{array}$ & $\begin{array}{l}\text { Physical screening including hop } \\
\text { tests (single, triple, side, crossover) }\end{array}$ & Speed test and direction change \\
\hline Original Score & $\%$ & 0 to 10 & Symmetry between limbs (\%) & Time \\
\hline \multirow[b]{2}{*}{$\begin{array}{l}\text { K-START score } \\
\text { (Knee Santy Athletic } \\
\text { Return to Sport) }\end{array}$} & 0 to 3 points & 0 to 3 points & 0 to 12 points (4 tests) & 0 to 3 points \\
\hline & $\begin{array}{c}0:<55 \% \\
1: \geq 55 \% \text { and }<63 \% \\
2: \geq 63 \% \text { and }<76 \% \\
3: \geq 76 \%\end{array}$ & $\begin{array}{c}0: 3 \geq \text { in the QASLS } \\
1: 2 \text { in the QASLS } \\
\text { 2: } 1 \text { in the QASLS } \\
0: 3 \text { in the QASLS } \\
\text { Extra penalty: } \\
-3 \text { points in case of } \\
\text { dynamic valgus. }\end{array}$ & $\begin{array}{c}0 \text { : pain prevents performance } \\
1: \leq 80 \% \\
2:>80 \% \text { and } 90 \% \leq \\
3: \geq 90 \%\end{array}$ & $\begin{array}{l}0: \text { pain prevents performance } \\
\begin{aligned} 1:>13.5 \mathrm{~s}> \\
2:>12 \text { and } \leq 13.5 \mathrm{~s} \\
3: \leq 12.5 \mathrm{~s}\end{aligned}\end{array}$ \\
\hline
\end{tabular}



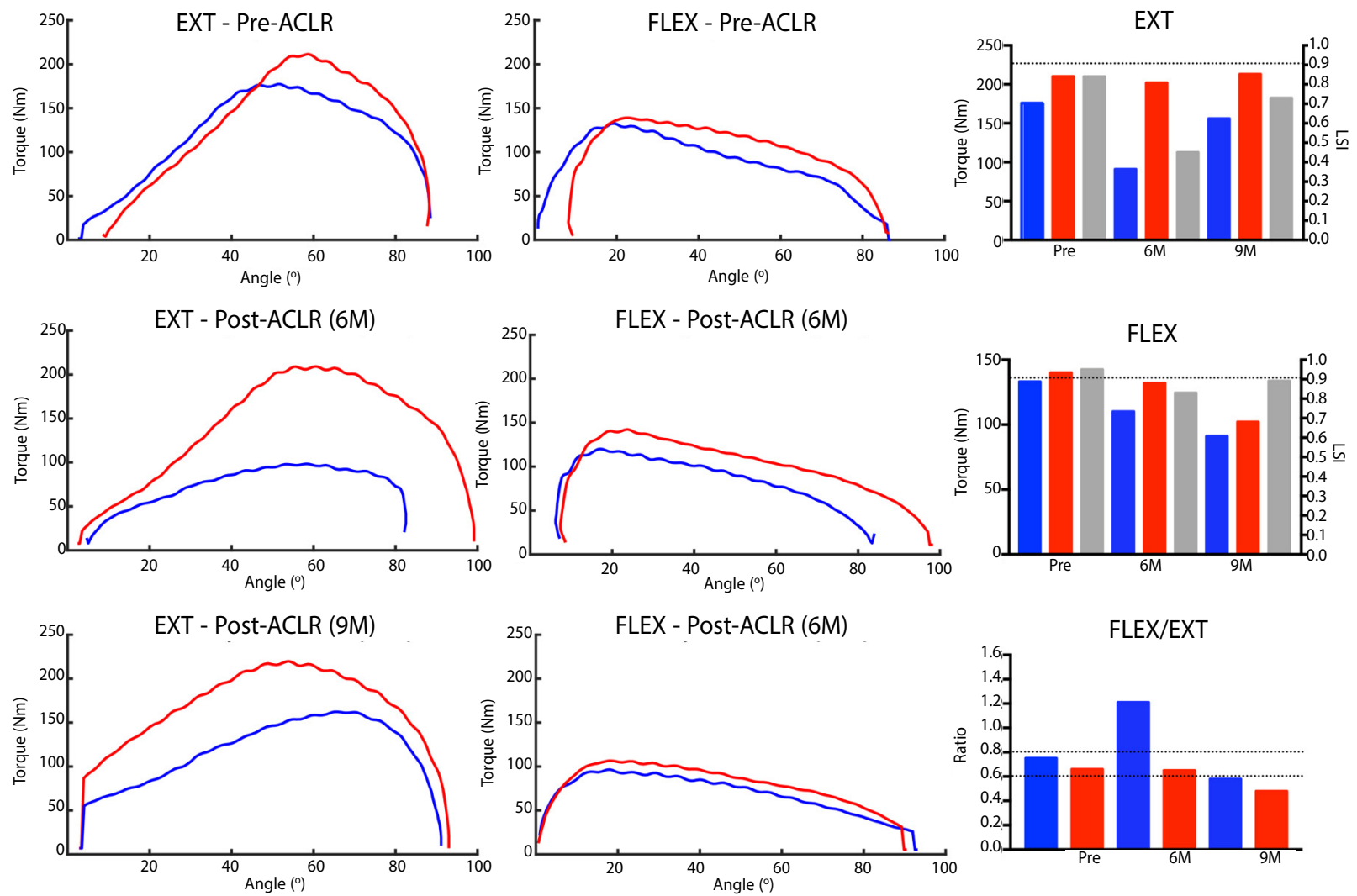

Anterior cruciate ligament reconstruction (ACLR), six months post-ACLR (6M), nine months post-ACLR (9M), Limb symmetry index (LSI), knee extension (EXT), knee flexion (FLEX), ratio between flexors and extensors (FLEX EXT). Blue lines and bars represent the contralateral limb, while red lines and bars represent the involved member (ACL). On the left side, the torque-angle curves measured for EXT and FLEX can be observed at different times. Peak torque and FLEX/EXT ratio values are shown on the right side of the bar graph. Note that the LSI is referenced to the right $y$-axis and the dashed lines mark the clinical criterion of the LSI $\geq 90 \%$ in the EXT and FLEX graphs. In the FLEX/EXT chart, the dashed lines represent the limits of $60-80 \%$

Figure 1. Example of isokinetic evaluation of knee extensors and flexors performed before and after ACL reconstruction.
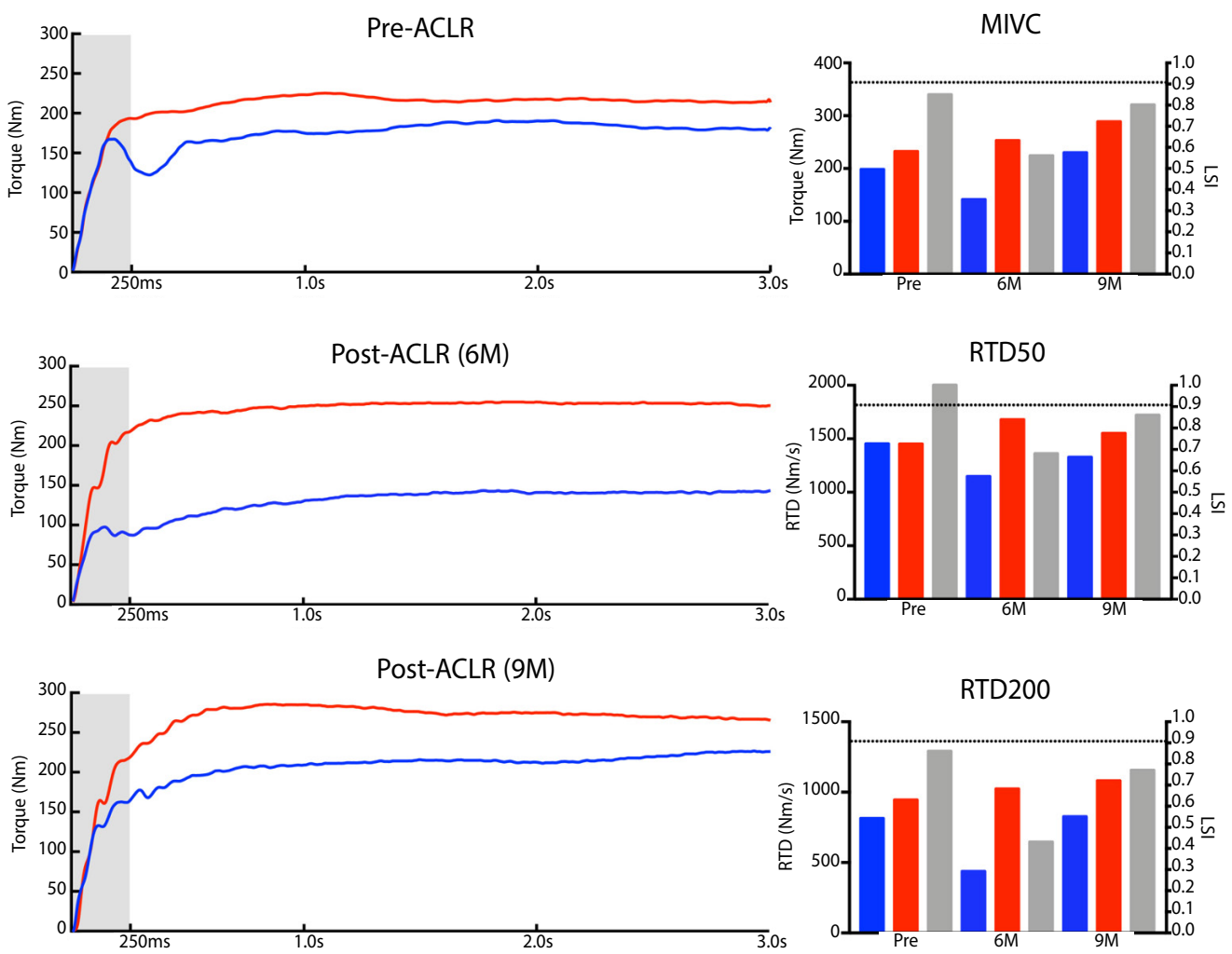

Anterior cruciate ligament reconstruction (ACLR), six months after ACLR (6M), nine months after ACLR (9M), Limb symmetry index (LSI), maximum isometric voluntary contraction (MIVC), rate of torque development (RTD), RTD measured in 50ms (RTD50, also called early RTD), RTD measured in 200ms (RTD200, also called late RTD). Blue lines and bars represent the contralateral member, while red lines and bars represent the involved member (ACL). On the left side, explosive torque curves measured for knee extension at different times can be observed. On the right side, the calculated values of MIVC and RTDs are shown through a bar graph. Note that the LSI is referenced to the right $y$-axis and the dashed lines mark the clinical criterion of the LSI $\geq 90 \%$. Note that the behavior of the RTD50 and RTD200 are different from each other and compared to MIVC.

Figure 2. Example of evaluation of the rate of torque development (RTD) of knee extensors performed in the pre and postoperative period of ACL reconstruction. 
Data suggest that maximum strength can be restored prior to RTD. ${ }^{65,66}$ Kuenze et al. ${ }^{65}$ observed the existence of a RTD deficit after one year of ACLR in athletes, even though they passed the $90 \%$ LSI criterion for maximum strength. Angelozzi et al. ${ }^{66}$ evaluated 45 professional soccer athletes who underwent the same post-ACLR rehabilitation/training protocol. They observed that in 6 months post-ACLR the maximum isometric strength of EXT reached the criterion of $90 \%$ of the LSI and with values close to those measured before the injury, but the RTD reached the release rates only after 12 months of the $A C L R$, with athletes performing a rehabilitation/training protocol focusing on the development of muscle power. Although few studies have evaluated post-ACLR RTD, the current findings underscore its importance and open space for further investigation.

\section{Aerobic criteria}

Despite the maximum $\mathrm{VO}_{2}\left(\mathrm{VO}_{2 \max }\right)$ expressing cardiovascular conditioning, little information is associated with RTP post-ACLR. Almeida et al. ${ }^{67}$ evaluated the $\mathrm{VO}_{2 \max }$ of 20 athletes post-ACLR in the pre- and after six months of $A C L R$. While the control group had an average $\mathrm{VO}_{2 \max }$ of $56.9 \mathrm{~mL} / \mathrm{kg} / \mathrm{min}$, the group with ACLR had $45.2 \mathrm{~mL} / \mathrm{kg} / \mathrm{min}$. Although the index improved after 6 months to $48.9 \mathrm{~mL} / \mathrm{kg} / \mathrm{min}$, it was still lower than the control group. The authors hypothesized that athletes with low $\mathrm{VO}_{2 \text { max }}$ are more likely to suffer a new ACL injury and that 6 months were insufficient to reach an acceptable $\mathrm{VO}_{2 \max }$ index suggesting postponement of the RTP. ${ }^{67}$

\section{Psychological aspects}

Psychological aspects are often overlooked in the RTP decision..$^{61,68}$ However, the literature mentions that $50 \%$ of athletes do not return to the previous competition level, mainly because of fear of a new injury, although they know their knees are able and prepared to resume physical activity post-ACLR. ${ }^{69-71}$ Therefore, it has been suggested that the psychological factor is one of the factors that most hamper the RTP post-ACLR. ${ }^{69,70}$ Tjong et al. ${ }^{69}$ report that fear of a new injury/pain, change of priority in life and the patient's personality are the three main psychological factors involved in RTP. ${ }^{69}$ Ardern et al. ${ }^{72}$ observed that the main deleterious causes for RTP were lack of confidence in the knee (28\%), fear of a new injury (24\%) and impaired knee function (22\%).

Personality and motivation play an important role in the post-ACLR rehabilitation process. ${ }^{68,73}$ Individuals with strong personal traits and highly competitive personalities or self-motivated are associated with a higher rate of RTP. ${ }^{68,73}$ On the other hand, the development of post-injury anxiety and depression is linked to a delay in post-ACLR rehabilitation. ${ }^{68,73}$
Therefore, motivational strategies throughout the rehabilitation/training process to combat fear, promote self-confidence and define personal goals have shown promising results in raising awareness of the injury and reducing athletes' anxiety. ${ }^{68,73}$

\section{Our experience}

We take into account the sport practiced for graft choice. For sports that require repeated jumping, such as basketball and volleyball, we avoid violating the extensor mechanism, giving preference to the flexor tendons. The same occurs for fighting athletes who make kneeling movements (eg. MMA, jiu-jitsu), given the common report of anterior knee pain post-ACLR with patellar graft. In athletes who need to do pivoting and sudden changes in direction (eg. soccer and rugby), we prefer to use the patellar or quadriceps graft to preserve the posterior thigh musculature and its synergistic function with the ACL.

Currently, for patients with explosive pivot (3+/3+), Segond fracture, age $<20$ years, generalized ligamentous hyper-laxity and in revision surgeries; we performed the tenodesis of the ilio-tibial band (ITB) as an associated lateral reinforcement (ALL). We always test the mobility of the meniscus, even if it does not present evident lesions. In case of any sign of hypermobility, we opted for the repair with an all-inside and/or inside-out and/or outside-in technique, according to the lesion pattern, aiming at stabilizing the meniscus-capsular insertion.

Undoubtedly, the subject "turn around time" is the most discussed in our service and always discussed with each athlete submitted to ACLR. After the ACLR, athletes are instructed to follow our Rehabilitation Protocol (Table 2). Prior to the release to the RTP, all clinical, functional, imaging (MRI) and isokinetic information of the athlete is discussed with the multidisciplinary group. It is worth mentioning that functional (questionnaires and jumps) and strength assessments are conducted pre- and post-ACLR. Post-ACLR assessments are carried out first at 6 months and successively every month until the target indexes are reached. We believe this to be the best practice and a determining factor for accumulating high RTP rates.

\section{CONCLUSION}

Guiding post-ACLR clinical practice during the RTP process is not an easy task and is constantly evolving. After reviewing the literature, together with the experience of our group, we concluded: the choice of graft must take into account the sport practiced; whenever possible, reconstruction of the ALL and suturing of the meniscus should be encouraged; the rehabilitation program must be structured in phases with objective progression criteria

Table 2. Rehabilitation protocol and postoperative follow-up for ACL reconstruction to return to play.

\begin{tabular}{|c|c|c|c|}
\hline Objectives & Activities & Devices & Progression \\
\hline $\begin{array}{l}\text { - Full ROM } \\
\text { - } \text { MS preserved }\end{array}$ & $\begin{array}{l}\text { - Weight Training } \\
\text { - ROM exercises }\end{array}$ & $\begin{array}{l}\text { - In physiotherapy } \\
\text { - At the gym } \\
\text { - At home }\end{array}$ & 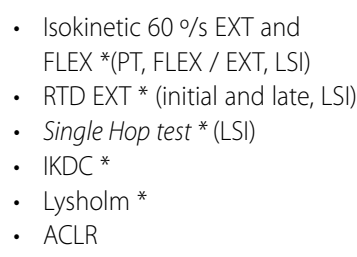 \\
\hline \multicolumn{4}{|c|}{ Phase 1: immediate post-surgery (d1 to $\mathrm{d} 10$ ) } \\
\hline $\begin{array}{l}\text { - Swelling reduction } \\
\text { - } \text { ROM } 0^{\circ} \text { to } 90^{\circ} \\
\text { - Muscle activation and } \\
\text { quadriceps motor control } \\
\text { - Safe walking (with } 2 \text { crutches) }\end{array}$ & $\begin{array}{l}\text { - } \text { Cryotherapy (>3x/day) } \\
\text { - Patellar mobilization } \\
\text { - } \text { ROM exercises } \\
\text { - } \text { Quadriceps isometric exercises } \\
\text { - } L S R \\
\text { - } \text { Weight shift exercises } \\
\text { - NMES }\end{array}$ & $\begin{array}{ll}\text { - } & \text { At home } \\
\text { - } 2 \text { crutches (WBAT) } \\
\text { - } & \text { Extension brace } \\
& \text { (withdraw for ROM gain) }\end{array}$ & $\begin{array}{l}\text { - } 10 \text { Postoperative days } \\
\text { - } \quad \text { LSR (3 active reps) }\end{array}$ \\
\hline
\end{tabular}




\begin{tabular}{c|c|c|c}
\hline Objectives & Activities & Devices & Progression \\
\hline
\end{tabular}

- Phase 2: initial rehabilitation (d10 to w3)

\begin{tabular}{|c|c|c|c|}
\hline $\begin{array}{l}\text { - Swelling reduction } \\
\text { - } \text { ROM } 0^{\circ} \text { to } 110^{\circ} \\
\text { - } \text { Quadriceps motor control } \\
\text { - } \text { Quadriceps muscle strength } \\
\text { - Safe walking (with } 1 \text { crutch) }\end{array}$ & $\begin{array}{l}\text { - } \text { Cryotherapy (>3x/day) } \\
\text { - Patellar mobilization } \\
\text { - } \text { ROM exercises } \\
\text { - } \text { LSR (in } 3 \text { directions) } \star \\
\text { - Knee extension (no load) } \\
\text { - } \text { Weight shift exercises } \\
\text { - } \text { Mini squats }\left(45^{\circ}\right) \star \\
\text { - NMES }\end{array}$ & 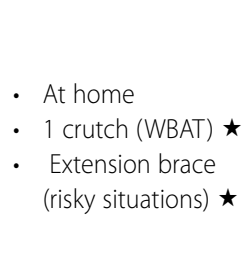 & $\begin{array}{l}\text { - } 3 \text { weeks post-ACLR } \\
\text { - } \text { Adequate gait pattern with } 1 \\
\text { crutch without immobilizer } \\
\text { - Withdrawal of stitches }\end{array}$ \\
\hline
\end{tabular}

- Phase 3: strengthening and neuromotor control (w3 to w6)

\begin{tabular}{|c|c|c|c|}
\hline $\begin{array}{l}\text { - Swelling resolution } \\
\text { - } \mathrm{ROM}>85 \% \text { of } \mathrm{CL} \text { limb } \\
\text { - } \mathrm{OL} \text { motor control } \\
\text { - } \text { OL MS gain } \\
\text { - Walking without crutches }\end{array}$ & $\begin{array}{l}\text { - } \text { ROM exercises } \\
\text { - } L S R \text { (in } 3 \text { directions) } \star \\
\text { - Knee extension (no load) } \\
\text { - Strengthening of calf, adductors } \\
\text { and hip abductors } \\
\text { - } \text { Weight shift exercises } \\
\text { - Mini squats }\left(45^{\circ}\right) \\
\text { - Standing knee flexion } \\
\text { - Pool walks } \\
\text { - Initial sensorimotor control }\end{array}$ & $\begin{array}{l}\text { - In physiotherapy } \\
\text { - } \text { Articulated brace } \\
\text { (risky situations) }\end{array}$ & $\begin{array}{l}\text { - } 6 \text { weeks post-ACLR } \\
\text { - } \text { Adequate walking pattern } \\
\text { without crutches } \\
\text { - } \text { Full ROM or }>85 \% \mathrm{CL} \\
\text { - Improved muscle trophism }\end{array}$ \\
\hline
\end{tabular}

\section{- Phase 4: advanced rehabilitation (w6 to w12)}

\begin{tabular}{|c|c|c|c|}
\hline $\begin{array}{l}\text { - OL MS gain } \\
\text { - Improvement of sensorimotor } \\
\text { and neuromuscular functions } \\
\text { - Gain of confidence in } \\
\text { the operated limb }\end{array}$ & $\begin{array}{l}\text { - Mini squats }\left(60^{\circ}\right) \\
\text { - Knee extension ankle weights } \\
\text { - Knee flexion ankle weights } \\
\text { - Strengthening of calf, adductors } \\
\text { and hip abductors } \\
\text { - Pool jogging } \\
\text { - Progress sensorimotor control } \\
\text { - Stacionary bicycle }(\mathrm{W} 8) \\
\text { - Treadmill (up to } 5 \mathrm{~km} / \mathrm{h}) \star\end{array}$ & - In physiotherapy & $\begin{array}{l}\text { - } 12 \text { weeks post-ACLR } \\
\text { - } \text { Single-leg squat (clean } \\
\text { or almost clean) } \\
\text { - Good gait pattern on the treadmill } \\
\text { - Good muscle trophism }\end{array}$ \\
\hline
\end{tabular}

\section{- Phase 5: return to activity (w12 to w24)}

\begin{tabular}{|c|c|c|c|}
\hline $\begin{array}{l}\text { - Complete restoration } \\
\text { of MS from OL } \\
\text { - Beginning of non- } \\
\text { competitive sporting } \\
\text { gestures (without turns) }\end{array}$ & $\begin{array}{l}\text { - Free OKC and CKC weight training machines } \\
\text { - Advanced sensorimotor control } \\
\text { - Start running on the treadmill (W16) } \\
\text { - } \\
\text { - Non-competitive gesture }(\mathrm{W} 18)^{*}\end{array}$ & $\begin{array}{l}\text { - In physiotherapy } \\
\text { - } \text { At the gym }\end{array}$ & $\begin{array}{ll}\text { - } & 24 \text { weeks post-ACLR } \\
\text { - } & \text { Isokinetic } 60 \% \text { /s EXT and } \\
& \text { FLEX\# (PT, FLEX/EXT, LSI) } \\
\text { - } & \text { RTD EXT\# (early and late, LSI) } \\
\text { - } & \text { Single Hop test } \text { (LSI) }_{\text {- }} \\
\text { - IKDC\# } \\
\text { - } & \text { Lysholm\# } \\
\text { - } & \text { Running on the treadmill }\end{array}$ \\
\hline
\end{tabular}

\section{- Phase 6: transition to sport (w24 or more)}

\begin{tabular}{|c|c|c|c|}
\hline $\begin{array}{ll}\text { - } & \text { Improve confidence } \\
\text { - } & \text { Ade return to play } \\
\text { sport-specific tasks } \\
\text { - } & \text { Explosive MS gain } \\
\text { - } & \text { Gradual return to sports activity }\end{array}$ & $\begin{array}{l}\text { - Maintenance of physical training - } \\
\text { Emphasis on explosive strength } \\
\text { - Plyometrics } \star \\
\text { - Changes in direction and turn } \star \\
\text { - Progressing sports gestures } \star\end{array}$ & $\begin{array}{l}\text { - } \text { At the gym } \\
\text { - In "field" }\end{array}$ & $\begin{array}{l}\text { - Optimal movement pattern for } \\
\text { specific pre-programmed tasks } \\
\text { - Athlete confidence }\end{array}$ \\
\hline
\end{tabular}

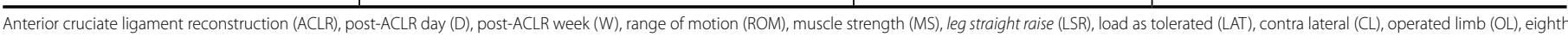

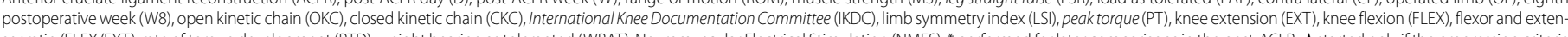

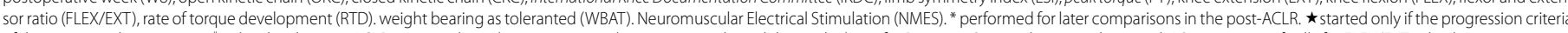

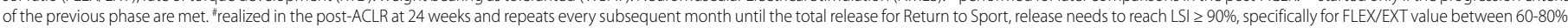

so that the athlete is treated/trained at the appropriate intensity, respecting the principle of overload. Subjective questionnaires should be incorporated, not just those established for functionality (eg, Lysholm and IKDC), as well as those for assessing psychological and trust aspects. Hop test and muscle strength measures are mandatory for understanding muscle function and dynamic joint stability. We believe these are the safest practices for the RTP.

\section{ACKNOWLEDGEMENTS}

The authors would like to thank Sidney Cavalcanti for his help in preparing the abstract in Spanish.

All authors declare no potential conflict of interest related to this article

AUTHORS' CONTRIBUTIONS: Each author made significant individual contributions to this manuscript. RG and VC: outlined the themes and subthemes. RG, VC, BF and JN: general review and final approval of the manuscript. VC: writing the functional evaluation topics, preparation of the images. BF: writing topics related to physiotherapy and functional evaluation, elaboration of the tables. RG, AC, GS, RB and JN were responsible for writing the medical and surgical topics. 


\section{REFERENCES}

1. Ellman MB, Sherman SL, Forsythe B, LaPrade RF, Cole BJ, Bach BR Jr. Return to play following anterior cruciate ligament reconstruction. J Am Acad Orthop Surg. 2015;23(5):283-96.

2. Webster KE, Feller JA. A research update on the state of play for return to sport after anterior cruciate ligament reconstruction. J Orthop Traumatol. 2019;20(1):10.

3. Morris RC, Hulstyn MJ, Fleming BC, Owens BD, Fadale PD. Return to Play Following Anterior Cruciate Ligament Reconstruction. Clin Sports Med. 2016;35(4):655-68.

4. Paterno MV, Huang B, Thomas S, Hewett TE, Schmitt LC. Clinical Factors That Predict a Second ACL Injury After ACL Reconstruction and Return to Sport: Preliminary Development of a Clinical Decision Algorithm. Orthop J Sports Med. 2017;5(12):1-7.

5. Grindem H, Snyder-Mackler L, Moksnes H, Engebretsen L, Risberg MA. Simple decision rules can reduce reinjury risk by $84 \%$ after $A C L$ reconstruction: the Delaware-Oslo $A C L$ cohort study. $\mathrm{Br} J$ Sports Med. 2016;50(13):804-8.

6. Burgi CR, Peters S, Ardern CL, Magill JR, Gomez CD, Sylvain J, et al. Which criteria are used to clear patients to return to sport after primary $\mathrm{ACL}$ reconstruction? A scoping review. Br J Sports Med. 2019;53(18):1154-61.

7. Ardern CL, Glasgow P, Schneiders A, Witvrouw E, Clarsen B, Cools A, et al. 2016 Consensus statement on return to sport from the First World Congress in Sports Physical Therapy, Bern. Br J Sports Med. 2016:50(14):853-64.

8. Kyritsis $\mathrm{P}$, Bahr R, Landreau $\mathrm{P}$, Miladi $\mathrm{R}$, Witvrouw E. Likelihood of $A C L$ graft rupture: not meeting six clinical discharge criteria before return to sport is associated with a four times greater risk of rupture. Br J Sports Med. 2016;50(15):946-51.

9. Barber-Westin SD, Noyes FR. Factors used to determine return to unrestricted sports activities after anterior cruciate ligament reconstruction. Arthroscopy. 2011;27(12):1697-705.

10. McCullough KA, Phelps KD, Spindler KP, Matava MJ, Dunn WR, Parker RD, et al. Return to high school-and college-level football after anterior cruciate ligament reconstruction: a Multicenter Orthopaedic Outcomes Network (MOON) cohort study. Am J Sports Med. 2012:40(11):2523-9.

11. Abrams GD, Harris JD, Gupta AK, McCormick FM, Bush-Joseph CA, Verma NN, et al. Functional Performance Testing After Anterior Cruciate Ligament Reconstruction: A Systematic Review. Orthop J Sports Med. 2014;2(1):232-5

12. Neeter C, Gustavsson A, Thomee P, Augustsson J, Thomee R, Karlsson J. Development of a strength test battery for evaluating leg muscle power after anterior cruciate ligament injury and reconstruction. Knee Surg Sports Traumatol Arthrosc. 2006;14(6):571-80

13. Dingenen B, Gokeler A. Optimization of the Return-to-Sport Paradigm After Anterior Cruciate Ligament Reconstruction: A Critical Step Back to Move Forward. Sports Med. 2017;47(8):1487-500.

14. Nawasreh Z, Logerstedt D, Cummer K, Axe M, Risberg MA, Snyder-Mackler L. Functional performance 6 months after $\mathrm{ACL}$ reconstruction can predict return to participation in the same preinjury activity level 12 and 24 months after surgery. Br J Sports Med. 2018;52(6):375.

15. Petersen W, Taheri P, Forkel P, Zantop T. Return to play following ACL reconstruction: a systematic review about strength deficits. Arch Orthop Trauma Surg. 2014;134(10):1417-28

16. Noyes FR, Barber SD, Mangine RE. Abnormal lower limb symmetry determined by function hop tests after anterior cruciate ligament rupture. Am J Sports Med. 1991;19(5):513-8.

17. Shelbourne KD, Gray T, Haro M. Incidence of subsequent injury to either knee within 5 years after anterior cruciate ligament reconstruction with patellar tendon autograft. Am J Sports Med. 2009;37(2):246-51.

18. Southam BR, Colosimo AJ, Grawe B. Underappreciated Factors to Consider in Revision Anterior Cruciate Ligament Reconstruction: A Current Concepts Review. Orthop J Sports Med. 2018;6(1):232-9.

19. Slone HS, Romine SE, Premkumar A, Xerogeanes JW. Quadriceps tendon autograft for anterior cruciate ligament reconstruction: a comprehensive review of current literature and systematic review of clinical results. Arthroscopy. 2015;31(3):541-54

20. Bjornsson H, Samuelsson K, Sundemo D, Desai N, Sernert N, Rostgard-Christensen L, et al. A Randomized Controlled Trial With Mean 16-Year Follow-up Comparing Hamstring and Patellar Tendon Autografts in Anterior Cruciate Ligament Reconstruction. Am J Sports Med. 2016;44(9):2304-13.

21. Conte EJ, Hyatt AE, Gatt CJ Jr, Dhawan A. Hamstring autograft size can be predicted and is a potential risk factor for anterior cruciate ligament reconstruction failure. Arthroscopy. 2014;30(7):882-90.

22. Legnani C, Zini S, Borgo E, Ventura A. Can graft choice affect return to sport following revision anterior cruciate ligament reconstruction surgery? Arch Orthop Trauma Surg. 2016;136(4):527-31.

23. Delaloye JR, Murar J, Gonzalez M, Amaral T, Kakatkar V, Sonnery-Cottet B. Clinical Outcomes After Combined Anterior Cruciate Ligament and Anterolateral Ligament Reconstruction. Tech Orthop. 2018;33(4):225-31.

24. Redler A, lorio R, Monaco E, Puglia F, Wolf MR, Mazza D, et al. Revision Anterior Cruciate Ligament Reconstruction With Hamstrings and Extra-articular Tenodesis: A Mid- to Long-Term Clinical and Radiological Study. Arthroscopy. 2018;34(12):3204-13.

25. Yoo JS, Kim SH, Park HG, Yoon SH, Park SG. Influence of anterolateral ligament injuries on stability and second-look arthroscopic findings after allograft transtibial anterior cruciate ligament reconstruction. Knee. 2019;26(1):132-41.

26. DePhillipo NN, Cinque ME, Chahla J, Geeslin AG, LaPrade RF. Anterolateral Ligament Reconstruction Techniques, Biomechanics, and Clinical Outcomes: A Systematic Review. Arthroscopy. 2017;33(8):1575-83

27. Smigielski R, Becker R, Zdanowicz U, Ciszek B. Medial meniscus anatomy-from basic science to treatment. Knee Surg Sports Traumatol Arthrosc. 2015;23(1):8-14

28. Di Vico G, Di Donato SL, Balato G, Correra G, D'Addona A, Maffulli N, et al. Correlation between time from injury to surgery and the prevalence of ramp and hidden lesions during anterior cruciate ligament reconstruction. A new diagnostic algorithm. Muscles Ligaments Tendons J. 2017;7(3):491-7.

29. Liu X, Feng H, Zhang H, Hong L, Wang XS, Zhang J. Arthroscopic prevalence of ramp lesion in 868 patients with anterior cruciate ligament injury. Am J Sports Med. 2011;39(4):832-7.
30. Sonnery-Cottet B, Conteduca J, Thaunat M, Gunepin FX, Seil R. Hidden lesions of the posterior horn of the medial meniscus: a systematic arthroscopic exploration of the concealed portion of the knee. Am J Sports Med. 2014;42(4):921-6

31. Sonnery-Cottet B, Saithna A, Blakeney WG, Ouanezar H, Borade A, Daggett M, et al. Anterolatera Ligament Reconstruction Protects the Repaired Medial Meniscus: A Comparative Study of 383 Anterio Cruciate Ligament Reconstructions From the SANTI Study Group With a Minimum Follow-up of 2 Years. Am J Sports Med. 2018;46(8):1819-26.

32. Katakura $M$, Horie $M$, Watanabe $T$, Katagiri $H$, Otabe $K$, Ohara $T$, et al. Effect of meniscus repair on pivot-shift during anterior cruciate ligament reconstruction: Objective evaluation using triaxial accelerometer. Knee. 2019:26(1):124-31.

33. Heilpern G, Stephen J, Ball S, Amis A, Williams A. It is safe and effective to use all inside meniscal repair devices for posteromedial meniscal 'ramp' lesions. Knee Surg Sports Traumatol Arthrosc. 2018;26(8):2310-6

34. Myer GD, Paterno MV, Ford KR, Quatman CE, Hewett TE. Rehabilitation after anterior cruciate ligament reconstruction: criteria-based progression through the return-to-sport phase. J Orthop Sports Phys Ther. 2006:36(6):385-402

35. Wilk KE, Arrigo CA. Rehabilitation Principles of the Anterior Cruciate Ligament Reconstructed Knee: Twelve Steps for Successful Progression and Return to Play. Clin Sports Med. 2017;36(1):189-232.

36. van Melick N, van Cingel RE, Brooijmans F, Neeter C, van Tienen T, Hullegie W, et al. Evidence-based clinical practice update: practice guidelines for anterior cruciate ligament rehabilitation based on a systematic review and multidisciplinary consensus. Br J Sports Med. 2016;50(24):1506-15.

37. Li Q, Zhang Y, Zhan L, Han Q, Wu M, Zhang N. Correlation Analysis of MRI-based Graft Maturity and Outcomes after Anterior Cruciate Ligament Reconstruction Using IKDC Score. Am J Phys Med Rehabilit. 2019.

38. Hofbauer M, Soldati F, Szomolanyi P, Trattnig S, Bartolucci F, Fu F, et al. Hamstring tendon autografts do not show complete graft maturity 6 months postoperatively after anterior cruciate ligament reconstruction. Knee Surg Sports Traumatol Arthrosc. 2019:27(1):130-6.

39. Biercevicz AM, Akelman MR, Fadale PD, Hulstyn MJ, Shalvoy RM, Badger GJ, et al. MRI volume and signa intensity of $\mathrm{ACL}$ graft predict clinical, functional, and patient-oriented outcome measures after $\mathrm{ACL}$ reconstruction. Am J Sports Med. 2015;43(3):693-9.

40. Grassi A, Bailey JR, Signorelli C, Carbone G, Tchonang Wakam A, Lucidi GA, et al. Magnetic resonance imaging after anterior cruciate ligament reconstruction: A practical guide. World J Orthop. 2016:7(10):638-49.

41. Harris JD, Abrams GD, Bach BR, Williams D, Heidloff D, Bush-Joseph CA, et al. Return to sport after ACL reconstruction. Orthopedics. 2014;37(2):e103-8.

42. Adams D, Logerstedt DS, Hunter-Giordano A, Axe MJ, Snyder-Mackler L. Current concepts for anterio cruciate ligament reconstruction: a criterion-based rehabilitation progression. J Orthop Sports Phys Ther. 2012:42(7):601-14.

43. Muller U, Kruger-Franke M, Schmidt M, Rosemeyer B. Predictive parameters for return to pre-injury level of sport 6 months following anterior cruciate ligament reconstruction surgery. Knee Surg Sports Traumatol Arthrosc. 2015;23(12):3623-31

44. Lynch AD, Logerstedt DS, Grindem H, Eitzen I, Hicks GE, Axe MJ, et al. Consensus criteria for defining 'successful outcome' after ACL injury and reconstruction: a Delaware-Oslo ACL cohort investigation. Br J Sports Med. 2015;49(5):335-42

45. Chmielewski TL, Zeppieri G Jr, Lentz TA, Tillman SM, Moser MW, Indelicato PA, et al. Longitudinal changes in psychosocial factors and their association with knee pain and function after anterior cruciate ligament reconstruction. Phys Ther. 2011:91(9):1355-66.

46. Zwolski C, Schmitt LC, Quatman-Yates C, Thomas S, Hewett TE, Paterno MV The influence of quadriceps strength asymmetry on patient-reported function at time of return to sport after anterior cruciate ligament reconstruction. Am J Sports Med. 2015;43(9):2242-9.

47. Ardern CL, Taylor NF, Feller JA, Whitehead TS, Webster KE. Psychological responses matter in returning to preinjury level of sport after anterior cruciate ligament reconstruction surgery. Am J Sports Med. 2013;41(7):1549-58

48. Silva LO, Mendes LMR, Lima POP, Almeida GPL. Translation, cross-adaptation and measurement properties of the Brazilian version of the ACL-RSI Scale and ACL-QoL Questionnaire in patients with anterior cruciate ligament reconstruction. Braz J Phys Ther. 2018;22(2):127-34.

49. Fitzgerald GK, Lephart SM, Hwang JH, Wainner RS. Hop tests as predictors of dynamic knee stability. J Orthop Sports Phys Ther. 2001:31(10):588-97.

50. Herrington L, Ghulam H, Comfort P. Quadriceps Strength and Functional Performance After Anterio Cruciate Ligament Reconstruction in Professional Soccer players at Time of Return to Sport. J Strength Cond Res. 2018.

51. Barfod KW, Feller JA, Hartwig T, Devitt BM, Webster KE. Knee extensor strength and hop test performance following anterior cruciate ligament reconstruction. Knee. 2019;26(1):149-54.

52. Hartigan EH, Axe MJ, Snyder-Mackler L. Time line for noncopers to pass return-to-sports criteria after anterior cruciate ligament reconstruction. J Orthop Sports Phys Ther. 2010;40(3):141-54

53. Blakeney WG, Ouanezar H, Rogowski I, Vigne G, Guen ML, Fayard JM, et al. Validation of a Composite Test for Assessment of Readiness for Return to Sports After Anterior Cruciate Ligament Reconstruction The K-STARTS Test. Sports Health. 2018;10(6):515-22.

54. Yuksel HY, Erkan S, Uzun M. Factors affecting isokinetic muscle strength before and after anterior cruciate ligament reconstruction. Acta Orthop Belg. 2011;77(3):339-48.

55. Zwolski C, Schmitt LC, Thomas S, Hewett TE, Paterno MV. The Utility of Limb Symmetry Indices in Return-to-Sport Assessment in Patients With Bilateral Anterior Cruciate Ligament Reconstruction. Am J Sports Med. 2016;44(8):2030-8.

56. Wellsandt E, Failla MJ, Snyder-Mackler L. Limb Symmetry Indexes Can Overestimate Knee Function After Anterior Cruciate Ligament Injury. J Orthop Sports Phys Ther. 2017;47(5):334-8. 
57. Soderman K, Alfredson H, Pietila T, Werner S. Risk factors for leg injuries in female soccer players: a prospective investigation during one out-door season. Knee Surg Sports Traumatol Arthrosc. 2001;9(5):313-21.

58. Bell DR, Trigsted SM, Post EG, Walden CE. Hip Strength in Patients with Quadriceps Strength Deficits after ACL Reconstruction. Med Sci Sports Exerc. 2016;48(10):1886-92.

59. Koga H, Nakamae A, Shima Y, I wasa J, Myklebust G, Engebretsen L, et al. Mechanisms for noncontact anterior cruciate ligament injuries: knee joint kinematics in 10 injury situations from female team handball and basketball. Am J Sports Med. 2010;38(11):2218-25.

60. Thomas AC, Villwock M, Wojtys EM, Palmieri-Smith RM. Lower extremity muscle strength after anterior cruciate ligament injury and reconstruction. J AthI Train. 2013;48(5):610-20.

61. Ardern CL, Webster KE, Taylor NF, Feller JA. Return to sport following anterior cruciate ligament reconstruction surgery: a systematic review and meta-analysis of the state of play. Br J Sports Med. 2011;45(7):596-606.

62. Huber R, Viecelli C, Bizzini M, Friesenbichler B, Dohm-Acker M, Rosenheck T, et al. Knee extensor and flexor strength before and after anterior cruciate ligament reconstruction in a large sample of patients: influence of graft type. Phys Sportsmed. 2019;47(1):85-90.

63. Maffiuletti NA, Aagaard P, Blazevich AJ, Folland J, Tillin N, Duchateau J. Rate of force development: physiological and methodological considerations. Eur J Appl Physiol. 2016;1 16(6):1091-116.

64. Buckthorpe M, Roi GS. The time has come to incorporate a greater focus on rate of force development training in the sports injury rehabilitation process. Muscles Ligaments Tendons J. 2017;7(3):435-41.

65. Kuenze C, Lisee C, Birchmeier T, Triplett A, Wilcox L, Schorfhaar A, et al. Sex differences in quadriceps rate of torque development within 1year of ACL reconstruction. Phys Ther Sport. 2019;38:36-43.

66. Angelozzi M, Madama M, Corsica C, Calvisi V, Properzi G, McCaw ST, et al. Rate of force development as an adjunctive outcome measure for return-to-sport decisions after anterior cruciate ligament reconstruction J Orthop Sports Phys Ther. 2012;42(9):772-80

67. Almeida AM, Silva PRS, Pedrinelli A, Hernandez AJ. Aerobic fitness in professional soccer players after anterior cruciate ligament reconstruction. PLoS One. 2018;13(3):e0194432.

68. Czuppon S, Racette BA, Klein SE, Harris-Hayes M. Variables associated with return to sport following anterior cruciate ligament reconstruction: a systematic review. Br J Sports Med. 2014;48(5):356-64.

69. Tjong VK, Murnaghan ML, Nyhof-Young JM, Ogilvie-Harris DJ. A qualitative investigation of the decision to return to sport after anterior cruciate ligament reconstruction: to play or not to play. Am J Sports Med. 2014;42(2):336-42

70. Ardern CL, Osterberg A, Tagesson S, Gauffin H, Webster KE, Kvist J. The impact of psychological readiness to return to sport and recreational activities after anterior cruciate ligament reconstruction. Br J Sports Med. 2014;48(22):1613-9.

71. Flanigan DC, Everhart JS, Pedroza A, Smith T, Kaeding CC. Fear of reinjury (kinesiophobia) and persistent knee symptoms are common factors for lack of return to sport after anterior cruciate ligament reconstruction. Arthroscopy. 2013;29(8):1322-9.

72. Ardern CL, Taylor NF, Feller JA, Webster KE. Fifty-five per cent return to competitive sport following anterior cruciate ligament reconstruction surgery: an updated systematic review and meta-analysis including aspects of physical functioning and contextual factors. Br J Sports Med. 2014;48(21):1543-52.

73. Ardern CL. Anterior Cruciate Ligament Reconstruction-Not Exactly a One-Way Ticket Back to the Preinjury Level: A Review of Contextual Factors Affecting Return to Sport After Surgery. Sports Health. 2015;7(3):224-30. 